\title{
A study of percutaneous k-wire fixation of supracondylar fracture in children in a tertiary care institute
}

\author{
Narendra Kumar ${ }^{1}$ \\ ${ }^{1}$ Assistant Professor, Department of Orthopaedics, Chirayu Medical College, Bhopal.
}

Address for Correspondence: Dr. Narendra Kumar, Assistant Professor, Department of Orthopaedics, Chirayu Medical College, Bhopal.

\begin{abstract}
Introduction: In orthopaedics practice Supracondylar fracture of humerus is the commonest injury around elbow in children during fall on the outstretched hand. The complications of this injury are many like pain, deformity and permanent restriction of movement however if due care is taken and early treatment is started, excellent results are seen. Various treatment modalities are used for treating these fractures. Closed reduction and percutaneous pinning is a useful technique to manage this condition. Methods: Thirty five cases with Gartland type III supracondylar humeral fractures were treated with closed reduction and percutaneous lateral pin fixation with Kirschner wire and followed up for 12 months. Results: Results were excellent in 30 patients and good in 4 patients according to Flynn's criteria. There was only one patient with poor results. Post-operatively, one patient sustained ulnar nerve injury. Two patients got pin tract infection which were superficial and healed after removing pins and antibiotics. Union was seen in all patients at the 2-3 weeks post-operatively before removing the K-wires. Conclusion: It is concluded that closed reduction and lateral pin fixation is a safe and effective treatment modality for management of supracondylar fractures with minimum complication rate.
\end{abstract}

Keywords: Supracondylar fractures of humerus, Closed reduction, Crossed pin fixation

\section{Introduction}

Most common fracture in children around the elbow is supracondylar fracture of humerus. Displaced supracondylar fractures have a high probability of neurovascular injuries and if not reduced and stabilized in optimal position may lead to serious residual deformity. The supracondylar fracture of humerus requires appropriate treatment because if it is not treated properly it may give rise to many complications such as Volkmann's ischemic contracture, neurovascular injury, myositis ossificans, stiffness of elbow and malunion [1]. Type 3 supracondylar fracture of humerus in children are usually treated by closed reduction and $\mathrm{K}$ wire fixation, open reduction and fixation is performed if adequate reduction cannot be obtained by manipulation $[2,3]$. With respect to cosmesis and functional results closed reduction and percutaneous pinning is the best modality to manage this case $[4,5]$ The purpose of this study is to assess the ability of closed reduction and

Manuscript received $25^{\text {th }}$ June 2016

Reviewed: $8^{\text {th }}$ July 2016

Author Corrected: $20^{\text {th }}$ July 2016

Accepted for Publication $2^{\text {nd }}$ August 2016 percutaneous lateral $\mathrm{K}$ wire fixation in management of supracondylar fracture.

\section{Materials and Methods}

Thirty five patients with type 3 supracondylar fracture humerus treated in Chirayu Medical College and hospital from June 2013 to February 2015 and followed for 12 months. Demographic profile, mode of injury, complications were recorded. Fracture was classified according to Gartland classification system [6]. Inclusion criteria were- Children between 5-16 years who had sustained type 3 supracondylar fracture humerus. Exclusion criteria were- Patients with pathological fractures, late presentations, open fractures, fracture extending to the intercondylar part of humerus and patients who required open reduction were excluded from study. All patients were operated within 24 hours of sustaining the injury. Under general anaesthesia, all cases were operated with closed manipulation and percutaneous $\mathrm{k}$-wire fixation under $\mathrm{C}$ - 
arm control and were immobilised in above elbow slab. Most patients were managed with one lateral and one medial $\mathrm{K}$ wire through respective epicondyles. After 3 weeks of immobilization active range of motion was started $\mathrm{K}$ wires and plaster were removed in the outpatient (OPD) clinic by four weeks when radiological union was confirmed. Elbow Range of motion exercises were started after removing the POP slab. Patients were followed-up on the 7 th day to inspect the wound. X-rays were taken after 2-3weeks; patients were followed up regularly to see the movement and carrying angle of the elbow. At 12 months patients were assessed clinically and radiologically and results were evaluated.

\section{Results}

Out of 35 children 20 were males and 15 were females. Children between 5 -16 years were included in study (mean age $11.2 \pm 1.4$ years). 28 children (80\%) sustained the injury following fall and 7 children (20\%) following RTA. Average duration of injury surgery interval was 18.2 hours. Post-operatively, one patient sustained ulnar nerve injury. Two patients got pin tract infection which were superficial and healed after removing pins and antibiotics. Union was seen in all patients at the 2-3 weeks post-operatively before removing the K-wires. Results were analyzed at 12 months using Flynn's criteria and graded as excellent, good, fair and poor. Results were excellent in 30 children (72\%), good in 4 $(11.42 \%)$ and poor in only $1(2.85 \%)$ patients. There were no complications like vascular injury, compartment syndrome, myositis ossifications, significant mal-union and non-union. None of the patients required a secondary procedure.

Table No 1: Age wise distribution of patients

\begin{tabular}{|c|c|c|}
\hline Age wise distribution of patient & No. of patients & Percentage \\
\hline $5-7$ & 3 & 22.85 \\
\hline $8-10$ & 8 & 34.28 \\
\hline $11-13$ & 12 & 34.28 \\
\hline $14-16$ & 12 & $\mathbf{1 0 0}$ \\
\hline Total & $\mathbf{3 5}$ & \\
\hline
\end{tabular}

Table No 2: Distribution of patients according to the mode of injury

\begin{tabular}{|c|c|c|}
\hline Mode of Injury & No. of patients & Percentage \\
\hline Fall from bicycle & 06 & 17.14 \\
\hline Fall while playing & 18 & 51.42 \\
\hline Fall from tree & 04 & 11.42 \\
\hline Road traffic accident & 07 & 20.00 \\
\hline Total & $\mathbf{3 5}$ & $\mathbf{1 0 0}$ \\
\hline
\end{tabular}

Table No 3: Distribution of patients according to the post-operative complications

\begin{tabular}{|c|c|c|}
\hline Post-operative complications & No. of patients (n/35) & Percentage \\
\hline Pin Tract infection & 2 & 05.71 \\
\hline Mal-union & 0 & 0 \\
\hline Iatrogenic ulnar nerve injury & 1 & 02.85 \\
\hline K wire displacement & 1 & 02.85 \\
\hline
\end{tabular}

Table No 4: Distribution of patients according to the result based on Flynn's Criteria

\begin{tabular}{|c|c|c|}
\hline Functional result based on Flynn's Criteria & No. of patients & Percentage \\
\hline Excellent & 30 & 11.42 \\
\hline Good & 4 & 00 \\
\hline Fair & 00 & 00 \\
\hline Unsatisfactory & 00 & 02.85 \\
\hline poor & 1 & $\mathbf{1 0 0}$ \\
\hline Total & $\mathbf{3 5}$ & \\
\hline
\end{tabular}




\section{Discussion}

Supracondylar fracture of humerus is the commonest injury around elbow in children during fall on the outstretched hand [7]. Late presentation of displaced supracondylar humeral fracture in a child is common in developing countries. Most commonly the modalities to treat this injury are closed reduction and cast application, skeletal traction, closed reduction and percutaneous $\mathrm{K}$ wire fixation. Its prognosis is unfavourable if the child presents more than one day after injury [8]

In this study of 35 patients 28 patients were injured due to fall, rest sustained RTA injury. In Edward [9] et al series 69 out of 78 patients sustained injury by fall and Fransworth reported 70\% injury by fall [10] Pin tract infection with pin loosening occurred in 2 cases which is comparable to Mostafavi study [11]. Pin tract infection necessitated earlier removal of K-wires (at 2 weeks). Infection was treated with antibiotics and regular dressing.

Many studies have shown like our series that two crossed pins placed from the medial and lateral condyles provide the greatest resistance to rotational displacement of the fracture fragment [12]. We had one iatrogenic nerve injury, it was probably due to overstrething of nerve while putting $\mathrm{K}$ wire, but patient recovered in 6 months. In kumar et al series similar results were seen [13].

The most common complication of supracondylar fractures of the humerus is malunion leading to cubitus varus deformity [14]. In our series no patient had this deformity. 30 patients had excellent result, four had good result and one patient had poor result on Flynn criteria because of severe soft tissue injury. Our study also supports the concept that early intervention of supracondylar fractures resulted in excellent clinical results and fewer complications.

\section{Conclusion}

From the present study it could be concluded that closed reduction and percutaneous lateral pin fixation is a safe and effective modality for the treatment of displaced supracondylar fractures.

With the advantages of decreased duration of hospital stay, stable fixation and early mobilization it also reduces the incidence of complications.
Funding: Nil, Conflict of interest: None initiated, Permission from IRB: Yes

\section{References}

1. Weiland AJ, Meyer S, Tolo VT, Berg HL, Mueller J. Surgical treatment of displaced supracondylar fractures of the humerus in children. Analysis of fifty-two cases followed for five to fifteen years. J Bone Joint Surg Am. 1978;60(5):657-61.

2. Flynn JC. Mathews JG, Benoit RL. "Blind pinning of displaced supracondylar fractures of the humerus in children". J Bone \& Joint Surg (Am), / 974; 56A: 263272.

3.AriñoVL, Lluch EE, Ramirez AM, FerrerJ, Rodriguez L, Baixauli F. Percutaneous fixation of supracondylar fractures of the humerus in children. J Bone Joint Surg Am. 1977 Oct; 59(7): 914-6.

4. Kaewpornsawan K. Comparison between closed reduction with percutaneous pinning and open reduction with pinning in children with closed totally displaced supracondylar humeral fractures: a randomized controlled trial. J Pediatr Orthop B 2001;10:131-7.

5. Boyd DW, Aronson DD. Supracondylar fractures of the humerus: a prospective study of percutaneous pinning. J Pediatr Orthop 1992;12: 789-94.

6. Gartland JJ. Management of supracondylar fractures of the humerus in children. Surg Gynecol Obstet. 1959;109:145-54.

7. Cheng JC, Lam TP, Shen WY. Closed reduction and percutaneous pinning for type III displaced supracondylar fractures of the humerus in children. J Orthop Trauma 1995; 9(6): 511-515.

8. Ating'a JE. Conservative management of supracondylar fractures of the humerus in Eastern Provincial General Hospital, Machakos. East Afr Med J 1984;61:557-60.

9. Edward E, Palmar, et al. Supracondylar fractures of the humerus. In children. JBJS 1978;60-A:652.

10. Farnsworth CL, Silva PD, Mubarak SJ. Etiology of supracondylar humerus fractures. J PediatrOrthop 1998;18(1):38-42. 
11. Mostafavi HR. and Spero C. "Crossed pin fixation of displaced supracondylar humerus fractures in children”. Clin Orthop, 2000; 376; 56-61.

12. Davis RT, Gorczyca JT, Pugh K. Supracondylar humerus fractures in children. Comparison of operative treatment methods. ClinOrthop Relat Res 2000; (376): 49-55.
13. Kumar R, Kiran EK, Malhotra R, Bhan S. Surgical management of the severely displaced supracondylar fracture of the humerus in children. Injury 2002;33(6):517-22.

14. Royce RO, Dutkowsky JP, Kasser JR, et al. Neurologic complications after K-wire fixation of supracondylar humerus fractures in children. J Pediatr Orthop 1991; 11 (2): 191-94.

\section{How to cite this article?}

Narendra Kumar. A study of percutaneous k-wire fixation of supracondylar fracture in children in a tertiary care institute. Int J Med Res Rev 2016;4 (7):1255-1258.doi:10.17511/ijmrr.2016.i07.31. 